\title{
A Trojan Horse? The Implications of Managerial Coaching for Leadership Theory
}

\author{
Valerie Anderson \\ University of Portsmouth
}

\begin{abstract}
This paper examines the behaviours associated with managerial coaching and assesses the implications for leadership theory. Survey data from 521 line-managers are analysed to: identify the behaviours associated with managerial coaching; examine factors that affect the propensity of managers to undertake coaching; and discuss the implications of the manager as coach role for leadership theory and practice. First, the analysis indicates that workplace coaching is distinct from specialised coaching practices. Second, demographic characteristics of individual managers, such as their age, experience or level of management qualification are unlikely to affect their propensity to undertake managerial coaching. However, leader-team member relationships (leader-member exchange) and occupational self-efficacy (OSE) are predictive of managerial coaching behaviours. Third, managerial coaching challenges traditional leader-centric models of leadership and requires an acknowledgement of reciprocity, collaborative 'meaning-making' and a diminished 'distance' between leaders and team members.
\end{abstract}

Key words: leadership theory; managerial coaching; leader-member exchange; occupational self-efficacy.

\section{Introduction}

This paper attempts to build a bridge between research and literature about managerial coaching and generic leadership theories. It examines the role of the manager as coach and the implications of managerial coaching for leadership theory and practice. Managerial coaching involves a supervisor or manager facilitating learning by enacting behaviours that enable employees to learn and develop work-related skills and abilities (Ellinger et al 2011, 67). Very little consensus is evident amongst scholars and practitioners about the distinction 
between leadership and management (Yukl 2008). In the context of workplace coaching, leadership is defined as: the interpersonal processes involved when the one person (variously referred to as a supervisor, team leader or line manager) enlists the support of their work group to achieve shared goals (McCartney and Campbell 2006). Advocates of managerial coaching highlight its potential to enable line-managers to fulfil their leadership function through developing and harnessing the skills, knowledge and abilities of team members to deliver motivated and effective performance (Harney and Jordan 2008; Gould-Williams and Gatenby 2010; Purcell and Hutchinson 2007).

In spite of the interest in the role of the manager as coach in both the leadership and HRD literatures very little attention has been paid to its implications for generic leadership theory (Hagen and Aguilar 2012; Ellinger et al 2011). In addition, although it is enacted by line managers, the literature relating to managerial coaching is grounded in the experience of specialist and executive coaches; there is scant research about the extent to which the same models and behaviours are appropriate for both 'specialised coaches' and for line managers (Sue-Chan et al 2010; Grant 2010; Peterson and Little 2005; Watson and Maxwell 2007) and little is known about the personal or professional characteristics that might affect the propensity for a manager to undertake workplace coaching (Ladyshewsky 2010; Heslin, Vandewalle and Latham 2006; Hawkins and Smith, 2006).

In this context the paper makes two principal contributions. First, it identifies the behaviours associated by line managers with workplace coaching and assesses factors that might affect managers' propensity to undertake coaching. Second, it assesses the implications of managerial coaching for generic leadership theory. The objectives of the paper are to:

(1) Identify the behaviours associated by managers with workplace coaching

(2) Examine the factors that affect the propensity of managers to undertake coaching

(3) Discuss the implications of managerial coaching for theories of leadership. 
The literature review addresses both coaching and leadership. First, issues relating to workplace coaching; the role and expectations of 'the manager as coach'; the organisational context in which managerial coaching occurs; and the factors that might affect the propensity of managers to undertake coaching are examined. A discussion of theories and research about leadership in work organisations follows that differentiates between models that are leadercentric and those that incorporate interaction and reciprocity. The study methods and survey data collection processes are then outlined. The findings and discussion sections consider the component features of managerial coaching followed by a section discussing the implications for leadership theory and practice. The argument presented here is that managerial coaching challenges leader-centric theories based on assumptions about 'heroic' leader figures and a hierarchical distance between leaders and followers. It is better understood within relational models of leadership that acknowledge reciprocal meaning-making systems developed by both leaders and their team members.

\section{Coaching and 'the manager as coach'.}

Coaching is now a prominent component of organisation-wide approaches to HRD. Executive and management level coaching are increasingly prevalent and many organisations also promote the idea of the 'manager as coach' (CIPD 2011; ASTD 2010; BlessingWhite 2009). Models of coaching in the practitioner literature are variously grounded in perspectives developed by coaching specialists and HRD or Organisation Development practitioners (see, for example, deHaan and Burger 2005; Griffiths and Campbell 2008). The human contact involved and the importance of maintaining high quality relationships between the coach and the 'coachee' mean that there are some similarities between coaching and psychotherapeutic traditions (Baron and Morin 2009). However, unlike other forms of therapy, workplace coaching is grounded in occupational settings and tends to be directive, 
future orientated and action-focused (Gray 2006; Segers, Vloeberghs and Henderickx 2011). Specialist coaching practitioners advocate a variety of methods that combine goal-focused and performance-driven approaches requiring different skills and behaviours (see, for example, Segers, Vloeberghs and Henderickx 2011; deHaan and Burger 2005; Griffiths and Campbell 2008). Behaviours and skills frequently cited as fundamental to coaching effectiveness are: productive and honest feedback; relational skills, analytical skills; observation and rapport (Baron and Morin 2009; De Jong, Leenders and Thijssen 1999; Ellinger, Hamlin and Beattie 2008). In addition, goal setting and a performance orientation; (Grant 2010; Griffiths and Campbell 2008) a development orientation, and an ability to enable 'coachees' to solve problems or take on new challenges have been advocated (Ellinger, Hamlin and Beattie 2008; Ladyshewsky 2010; Liu and Batt 2010; Mavor, SaddlerSmith and Gray 2010). In spite of the proliferation of practice based models of coaching, however, its theoretical grounding remains elusive; a descriptive approach is taken to required behaviours and the extent to which specialised coaching overlaps with managerial coaching is unclear (Jackson 2005; Griffiths and Campbell 2008; Ives 2008).

Although managerial coaching is increasingly advocated in organisations the function and context of leadership and management is distinct from specialised coaching. Managerial coaching forms one element of demanding requirements for leaders to improve employees' skills; motivate them to exert discretionary effort; and provide job opportunities to enable them to make use of their skills, knowledge and attributes (Harney and Jordan 2008; GouldWilliams and Gatenby 2010; Purcell and Hutchinson 2007). In contrast to specialist coaches, line managers have different expectations about the form and content of their workplace interactions. Specialised coaching typically involves 'sit-down' sessions but line manager exchanges with their staff are more likely to take the form of informal, occasional or even opportunistic interactions forming part of performance management activities that may not 
even be identified by those involved as constituting an organised coaching process (Grant 2010; Hamlin, Ellinger and Beattie 2008; Heslin, Vandewalle and Latham 2006; Ives 2008; McGuire, Stoner and Myloner 2008). However, much of the literature relating to managerial coaching is grounded in the experience of specialised and executive coaches and there is scant research about the processes involved and the extent to which the same models and principles are appropriate for both specialised coaches and for line managers (Watson and Maxwell 2007; Peterson and Little 2005; de Jong, Leenders and Thijssen 1999). The first objective of this paper, therefore, is to identify the behaviours associated by managers with workplace coaching and the extent to which these differ from those indicated in the specialised coaching literature.

The contextually grounded nature of managerial coaching also gives rise to questions about its applicability to all those in leadership or managerial positions. This informs the second objective of this paper which addresses the propensity of managers to engage with workplace coaching. Biographical and demographic characteristics, such as age, gender and experience in a managerial role have been suggested as issues that affect propensity to coach (Ladyshewsky 2010; Heslin, Vandewalle and Latham 2006; Hawkins and Smith 2006) but they have so far received scant systematic exploration. In addition, a consistent feature in the coaching literature is the importance of self-awareness by those involved in the process, both as coach and as 'coachee' (Ellinger et al 2011; McLean at al 2005). In exploring this feature research has suggested that occupational self-efficacy (OSE) may be an important variable (Nielson and Munir 2009). OSE refers to the extent of an individual's confidence in their ability to carry out their job role (Bandura 1977). Self-efficacy is frequently cited as a moderating factor in work design, management style and performance-orientated studies (Griffin and Hesketh 2003; Sivanathan et al 2004) and has been shown to be an important factor in executive coaching processes (Baron and Morin 2009). It may well be a prerequisite 
for productive managerial coaching exchanges (Sue-Chan, Chen and Lam 2011; Kark and Van Dijk 2007) although no evidence about the relationship between OSE and managers' propensity to undertake workplace coaching has yet been published. This gap in knowledge underpins the second objective of the paper: to examine the factors that affect the propensity of managers to undertake coaching, specifically variables such as age, gender, position in the organisational hierarchy, experience in a managerial role and OSE.

\section{Managerial coaching and theories of leadership}

Although managerial coaching is enacted by those fulfilling leadership roles there has been scant consideration of the implications of the manager as coach role for theories of leadership (Hagen and Aguilar 2012; Ellinger et al 2011). This gap is addressed by the third objective of this paper. Seminal theories have variously focused on the traits, behaviours, functions and contingencies of leadership. Although differently expressed, models derived from these theories have consistently placed leaders themselves at the heart of the analysis. In more recent years this leader-centric approach has found popular expression through models of leadership evoking qualities of: transformation, vision, inspiration, and charisma (Yukl 2008). These approaches focus on symbolic and emotional leadership qualities involving: the development and communication of a challenging and attractive vision; the expression of qualities such as confidence, decisiveness and optimism; and role modelling of changeoriented behaviours. From its initial formulation in the field of organisational psychology in the early 1980s (Burns 1978; Bass 1985) advocates of transformational leadership have claimed it to be positively associated with wide variety of individual, group and organisational performance improvements following from transformed levels of motivation and purpose amongst followers (Avolio, Walumbwa and Weber 2009; Bass and Avolio 1994). At the heart of these and other 'new genre' models such as 'authentic' leadership and 
'servant' leadership (Avolio and Gardner 2005; Greenleaf 2002; Russell and Stone 2002) there is the assumption that leaders are autonomous agents, wholly responsible for the behaviour of their otherwise passive team members or followers. These approaches to leadership represent a popular strand in the practitioner literature (Hartog, Caley and Dewe 2007) but they are conceptually problematic and studies have suggested that they have limited explanatory power (Felfe and Schyns 2006; Piccolo and Conquitt 2006). Other critics (see, for example, McCauley et al 2006, Yukl, O'Donnel and Taber 2009) highlight the extent to which leader-centric and 'heroic' approaches to leadership underestimate the collective features of leadership and the social and reciprocal nature of relationships between leaders and their team members (Moss, Dowling and Callanan 2009; Stewart and Johnson 2009).

A challenge to the leader-centric approach is presented by models that highlight the potential for collective or distributed features of leadership processes. These approaches conceptualise leadership as a shared phenomenon that occurs through distributed social networks where, in addition to a formally appointed manager, informal leaders can emerge. Conflict within workgroups can occur where competition between different leadership figures arises, but social network analysis of group processes also highlights the positive potential for performance where appointed and emergent leaders are able to achieve reciprocal and synchronised influence on the achievement of workgroup objectives (Mehra et al 2006).

A further challenge to leader-centric approaches is offered by those who highlight the important effects of team members' implicit 'schemas' of leadership. These theories highlight how group members' assumptions and beliefs about the attributes that leaders should possess; what to expect and how to respond affect group and individual performance (Shondrick, Dinh and Lord 2010; Fiske and Taylor 2008). Other cognitive approaches to leadership also focus on the requirement for perceptual reciprocity between leaders and 
followers, highlighting how interactions between leaders and team members constitute an important part of meaning-making for both parties within the work and employment relationship (Valcea et al 2011).

These interactive approaches are developed further in social exchange theories of leadership which provide a basis for an analysis of the reciprocal exchange processes involved and the consequences for co-workers, leaders and members of work groups (Meinal, Ehrlich and Dukerich 1987; Grint 2005). In particular research into leader-member exchange (LMX) highlights the role of 'dyadic' relational expectations between leaders and followers (Kang and Stewart 2007; Sparrowe and Liden 1997) and the quality of interactions experienced over time which provide the basis for meaningful emotional support and exchange leading to mutual respect, trust and loyalty (Burns and Otte 1999; Kang and Stewart 2007; O’Donnell, Yukl and Taber 2012). Positive LMX has been shown to have an influence on employee performance regardless of whether the relationship quality was reported by the leader or the subordinate and studies also suggest a positive correlation with job satisfaction, organisational engagement and employee creativity (Liao et al 2010). The LMX approach provides a useful lens through which coaching by line managers can be viewed although the likelihood that it affects a managers' propensity to engage with the process has not yet been examined.

This brief overview of different theories of leadership has important implications for leadership practice and interest in workplace coaching has increased alongside these debates but limited attention has thus far been paid to the areas of overlap between coaching and leadership theory (Hagen and Aguilar 2012; Ellinger et al 2011; Hamlin, Ellinger and Beattie 2006).

\section{Study methods and data collection}


The survey research reported here investigated managerial coaching as an integrated feature of management activities. The research framework incorporated descriptive and explanatory questions. First, what behaviours are associated by managers with workplace coaching? Second, is there a relationship between individual demographic factors and the propensity to engage with managerial coaching? Third, do OSE and LMX increase the propensity of managers to engage with managerial coaching?

\section{The measures}

Data relevant to the first question in the research framework were gathered through twelve pre-validated items utilising a 4 point scale. These items comprised coaching-related behaviours consistently highlighted in the specialised coaching literature: giving and receiving feedback; effective listening; mutual support/rapport; commitment to dialogue; planning and goal-setting; development orientated behaviours, and performance orientated behaviours (McLean et al 2005; Ellinger, Ellinger and Keller 2005; Hawkins and Smith 2006; de Haan and Burger 2005; BlessingWhite 2009). The literature suggests that managerial coaching is often informal and implicit such that line managers may not identify their workplace behaviours as constituting an organised coaching process (Hamlin, Ellinger and Beattie 2008; Ives 2008) and so the wording of these items referred to 'management behaviours' rather than specifically to 'coaching'.

Data for the second question in the research framework, the relationship between individual demographic characteristics and the propensity to undertake managerial coaching, were gathered through categorical questions relating to gender, age $(25-34 ; 35-44 ; 45-54 ; 55$ 64 years); length of management experience (less than 3 months; 3 months -1 year; $1-5$ years; more than 5 years); level in the organisational hierarchy $\left(1^{\text {st }}\right.$ line manager; middle manager; top level / Board manager) and level of UK management qualification (none; 
National Vocational Qualification (NVQ) level 2; NVQ level 3; NVQ level 4; Business Qualification e.g. Degree, DMS, CIPD).

Data relevant to the third question in the research framework, the extent to which OSE and LMX increase the propensity of managers to engage with managerial coaching, were gathered through pre-validated scales. LMX was measured through six items from Graen and Uhl-Bien (1995) and Liden and Maslyn (1998) with a 7-point Likert-type response format. In this study a Cronbach alpha of .865 is reported for the scale. Occupational selfefficacy was measured through six items from Bandura (1997) as further developed by Rigotti and Schyns (2008) with a 6-point Likert-type response format. This scale achieved a Cronbach alpha of .847.

\section{The sample}

The research was conducted in 2009. A survey methodology using a secure on-line questionnaire was adopted to reach a broad cross-section of line managers working in multiple public, private and not-for-profit organisations in the UK. The sample of participating organisations was purposive: organisations known to be interested in coaching at work agreed to participate in the project after learning about the research at conferences and through professional interest groups connected with coaching at work. Ten UK organisations agreed to participate and the HR contact in each organisation acted as the 'gate keeper' to line managers who were given a URL link to the online survey relating to their managerial experiences during the previous three-month period. An overview of the participating organisations is shown in Table one.

\section{Put table one here}

Five of the participating organisations were from the private sector; two were from the public sector and a further three were not-for-profit organisations. Four of them were small 
organisations and the remaining six employed more than 500 people. A total of 535 questionnaires were completed of which fourteen responses were deemed ineligible. Given the on-line nature of the survey and the access through one independent gate keeper in each participating organisation it is not possible to estimate the proportion of managers from each organisation who responded. Wide variations in response levels were recorded between participating organisations and two large organisations (one from the public sector and one from the private sector) accounted for over fifty percent of the responses. Eighteen percent of respondents were from small organisations. Taken as a whole, the respondent pool was divided almost equally between male and female (52:48 percent). Ten percent of respondents were senior or board level managers; 48 percent were at middle management level and 42 percent were first-line managers. Half of the respondents (51.7 percent) had been in their current management role for between one and five years; 30.9 percent had been in post for more than five years and 17.9 percent for less than one year. The majority of respondents (66.8 percent) were between 35-55 years old; 19.5 percent of respondents were younger than 35 and 13.8 percent were older than 55 years. Almost half of the line managers in the sample (46.3 percent) reported that they had no formal management qualification. A wide variation in the number of direct reports was evident; the median was seven and the mode was four.

\section{Results and findings}

The data were analysed in the following ways. Principal component analysis was conducted to address the first question in the research framework to identify the managerial behaviours that collectively represent managerial coaching and the extent to which these differ from those indicated in the specialised coaching literature. To address the second question of the research framework (the relationship between individual demographic factors and propensity to undertake managerial coaching) a regression analysis was undertaken with individual 
demographic factors as controls. To address the third question of the research framework a step-wise multiple regression analysis was conducted to assess the extent to which LMX and OSE increase the propensity for managers to undertake workplace coaching.

\section{Managerial coaching behaviours}

The principal component analysis was conducted on the 12 coaching behaviour items to assess the extent to which responses formed a coherent cluster and to assess the variance accounted for by each of the items. A Cronbach Alpha test of reliability was also applied to each of the clusters (see Table two).

\section{Put table two here}

Table two indicates one component group comprising five items is identified with an acceptable level of reliability $(\alpha=.78)$. These five items represent: a development orientation ('I have helped them all develop themselves as individuals' and 'I actively help them all find and get training / learning to improve their performance and skills'); feedback ('I am very conscientious in giving them all feedback on their work - positive and negative); a performance orientation ('I am very good at observing their work to guide my management of them'); and planning and goal-setting (I am very good at helping them all to express their own action plans). Items representing other behaviours derived from the specialised coaching literature failed to load into any coherent grouping with an acceptable level of reliability (taken as $\alpha=.6$ or higher). The analysis confirms, therefore, that managerial coaching does not represent the full range of specialised coaching processes but involves a more focused range of behaviours comprising: a development orientation, a performance orientation, planning and goal setting, and feedback processes. 


\section{Propensity to undertake managerial coaching}

The next stage of the analysis assessed whether the behaviours identified through the principal component analysis (labelled as core managerial coaching and subsequently treated as a scale) are affected by demographic factors. A regression analysis was conducted using core managerial coaching as the dependent variable and individual biographical factors (gender; age; seniority; level of management qualification; length of managerial experience) as predictors. This indicated that demographic characteristics account for less than 3 percent of variance. The Spearman correlation test for non-parametric data (Table three) was also used to examine the association between a wider range of variables and core managerial coaching. This confirmed the lack of direct association of demographic variables with reported core managerial coaching but did suggest a positive association with OSE.

\section{Put table three here}

A stepwise multiple regression analysis (table four) was then undertaken to assess the extent to which LMX and OSE combined to contribute to managerial coaching. This indicates that OSE and LMX account for 26 percent of variance (Adjusted R Square $=0.268$; for OSE $\mathrm{F}=121.3$; for $\mathrm{LMX} \mathrm{F}=83.0$ ).

\section{Put table four here}

Taken as a whole the analysis indicates that core managerial coaching behaviours reported by managers comprise: a development orientation, a performance orientation, planning and goal setting, and feedback processes. Demographic factors (age, gender, seniority; experience, level of formal managerial qualification) do not affect the likelihood that managers will engage with managerial coaching. With the exception of a small association between core managerial coaching and gender and the number of direct reports very little correlation is evident with individual demographic factors. However, LMX and OSE are shown to increase 
the propensity for managers to undertake workplace coaching.

\section{Discussion}

Managerial coaching is increasingly expected in employing organisations (CIPD 2011; BlessingWhite 2009) and research suggests that it forms an important part of expected leadership processes in a wide range of different national cultural contexts (see, for example, Garavan et al 2008; Choi, Jun and Jeung 2012; Noer, Leupold and Valle 2007; ASTD 2010). Although ideas about managerial coaching are predicated by humanistic interpretations of management and leadership practice (Ladyshewsky 2010; Wakefield 2006) very little is known about the micro behaviours that comprise the manager as coach role, something that is addressed in this section of the paper.

In relation to the first objective the analysis indicates that managerial coaching is distinctively different from coaching activities undertaken by external or internal specialised coaches. From the perspective of the coaching literature one interpretation of the findings is that managerial coaching may be understood as a limited' or 'cut-down' version of specialised coaching. However, if managerial coaching is conceptualised as part of leadership practice, then it is not a limited version of specialised coaching and the behaviours identified are fundamental to workplace development processes required for individual and firm performance (Gould-Williams and Gatenby 2010; Purcell and Hutchinson 2007). Managerial coaching distinctively focuses on behaviours associated with: a performance orientation, goal-setting and planning, a development orientation and giving effective feedback. The identification of these behaviours indicates that manager as coach is better understood through the 'lens' of leadership practice than through the perspectives of the specialised coaching literature. 
In relation to the second objective the analysis indicates that individual demographic factors have little influence on the propensity of a manager to undertake coaching. This paper also represents the first attempt to examine the relationship between managers' occupational self-efficacy and the likelihood that workplace coaching will be undertaken. Research has shown increased levels of occupational self-efficacy by those who are coached (see, for example, Baron and Morin 2009; Hodgetts 2002; Nielson and Munir 2009) but this paper contributes an assessment of its importance from the perspective of the coach. This is in line with the emphasis in the coaching literature on the need for a sense of mutuality and selfawareness in the relationship between the coach and the 'coached' (Grant 2007; McLean et al 2005; de Haan and Burger 2005). Although a range of external and internal cultural factors will affect the extent to which managerial coaching may be undertaken, OSE is shown to be important for workplace coaching. This lends support to models of leadership that acknowledge the importance of a leader's reflexive 'order of development' (McCauley et al 2006) .

In relation to the third objective the paper highlights the extent to which the assumptions of leader-centric theories, which are prevalent in many organisations, are challenged by the requirements of managerial coaching. The analysis suggests that managerial coaching is not a one-way, directive, performance driven management tool. The regression analysis highlights the importance of both OSE and LMX. Although managerial coaching may resemble informal and implicit activities (McGuire, Stoner and Myloner 2008; Larsen and Brewster 2003; Kulik and Bainbridge 2006; Heslin, Vandewalle and Latham 2006) rather than planned and formal coaching sessions, these interactions are built on experiences from months or years of managers working with their team members incorporating past evaluations of performance as well as both positive and negative feedback exchanges (Zagenczyk et al 2009). These processes are affected by the quality of 
relationships with subordinates (Gregory and Levy 2010; London and Smither 2002). To be successful managerial coaching requires an acceptance of relational and social constructivist features of leadership processes where the hierarchical space between leaders and followers is diminished and the potential for growth, development, challenge and change to both parties involved in the process is acknowledged.

\section{Implications}

The manager as coach role takes place in dynamic and often ambiguous contexts. It is increasingly advocated in organisational contexts of: increasing decentralisation and delayering (Ellinger, Hamlin and Beattie 2008, Kulic and Bainbridge 2006); individualisation of the employment relationship and the devolution of HR responsibilities to line managers and others with leadership responsibilities (Keegan, Huemann and Turner 2012). This analysis suggests that managerial coaching presents a challenge to leader-centric and 'heroic' leadership models. It requires an acknowledgement of the relational and reciprocal features of leadership recognising the potential for personal change and development by both leaders and team members through prolonged interactions that affect sense-making at the operational level. The positioning of managerial coaching as a feature of leadership practice has consequences for HRD practice as well as for leadership theory.

First, the research illuminates the contextual and situational factors affecting managerial coaching. Second, the importance of LMX and OSE indicate that managerial coaching may be inhibited in individualised and competitive work cultures (Ellinger, Ellinger and Keller 2005; Kulick and Bainbridge 2006). In a context of rapid change in organisations and frequent role changes for managers, attention to the effect on managerial self-efficacy and leader-team member relationship building is important if managerial coaching is to be effective. However, whilst OSE and LMX represent important predictors of a propensity to undertake managerial coaching the analysis indicates that they represent only 26 percent of 
variance and further research is necessary into the factors that both encourage and inhibit managerial coaching.

Third, to be effective, managerial coaching must be undertaken in alignment with other organisational investments in HRD (Ellinger et al 2011). Some research studies suggest managerial coaching is more effective and more feasible in collaborative or collectivist work and cultural environments (Noer, Leupold and Valle 2007). The analysis presented here lends support to the requirement for further research into the workplace coaching micro-behaviours involved in different cultural and organisational contexts (Hagen and Aguilar 2012). Fourth, disruption to the composition of teams (Stoker 2008) and the increasing numbers of people to be coached in delayered organisations may create difficulties for organisations that wish to promote a managerial coaching culture.

\section{Conclusion}

This paper represents a bridge between research and literature about managerial coaching and generic leadership theories. It sets out to: identify the behaviours associated by managers with workplace coaching; examine the factors that affect the propensity of managers to undertake coaching; and discuss the implications of managerial coaching for theories of leadership.

A number of limitations that affect its generalisability are acknowledged. First, the perceptual nature of the data and the self-reporting features of the research affect the validity of the study. Second, given the cross-sectional nature of the research, trends and causality cannot be established and the UK basis of the sample limits the extent to which findings can be generalised on an international or cross cultural basis. A third limitation is the purposive nature of the organisational sample and the lack of clarity about the proportion of respondents from each participating organisation although the total number of achieved responses is sufficient to draw some general conclusions. 
However, the analysis supports the conclusion that the adoption of managerial coaching as an HRD strategy presents a challenge to popular expectations of leadership. Indeed, managerial coaching may well represent a 'Trojan horse'. Organisations that are attracted to the performative promise of managerial coaching may well discover that an unintended consequence is a requirement for a radical review of ideas prevalent in contemporary leadership literature and practice that assume passivity amongst team members and ascribe a hierarchical distinction towards leaders who have been appointed for, or are expected to develop, their charismatic or transformational qualities.

Managerial coaching is a two-way reciprocal process. It takes place in complex and demanding contexts where leaders have to motivate team members; improve their skill levels and provide opportunities for them to make effective use of their skills, knowledge and attributes. It also requires an acceptance of mutuality between the coach and the 'coached' and acknowledgement of processes of interaction over a sustained period that have the potential to generate new understanding and to challenge the values and attitudes of both the leader and the team member. Organisations that decide to pursue an HRD strategy of managerial coaching alongside tacit or explicit expectations of transformational or other leader-centric practices may get more than they expect. To be effective managerial coaching requires a fundamental reconsideration of models of leadership and a corresponding review of leadership development.

\section{Acknowledgement}

The research reported in this paper was carried out as part of a study conducted by researchers from Portsmouth Business School and commissioned by the UK Chartered Institute of Personnel and Development (www.cipd.co.uk) on 'Coaching at the Sharp End'. 


\section{REFERENCES}

American Society for Training and Development. 2010. The ASTD WLB competency model. http://www.astd.org/content/research/competency/AreasofExpertise.htm.

Avolio, B.J. and W.L. Gardner. 2005. Authentic leadership development: getting to the root of positive forms of leadership. The Leadership Quarterly 16, no. 3: 315-338.

Avolio, B. J., F.O. Walumbwa, and T.J. Weber. 2009. Leadership: Current theories, research, and future directions. Annual Review of Psychology, 60: 421-449.

Bandura, A. 1997. Social Learning Theory. Englewood Cliffs, NJ: Prentice Hall.

Baron, L. and L. Morin. 2009. The Coach-Coachee Relationship in Executive Coaching: A Field Study. Human Resource Development Quarterly 20, no. 1: 85-106.

Bass, B. M. 1985. Leadership and Performance. N.Y: Free Press.

Bass, B.M. and B.J. Avolio (Eds.). 1994. Improving organizational effectiveness through transformational leadership. Thousand Oaks, CA: Sage.

BlessingWhite. 2009. The Coaching Conundrum 2009: Building a Coaching Culture that Drives Organizational Success. Princetown, NJ. http://www.blessingwhite.com/CC_report.asp.

Burns, J.M. 1978. Leadership. New York: Harper and Row.

Burns, J.Z. and F. L. Otte. 1999. Implications of leader-member exchange theory and research for human resource development research. Human Resource Development Quarterly 10, No. 3: 225-48.

Chartered Institute of Personnel and Development. 2011. The Coaching Climat., London: CIPD.

Choi , M., H. Jun, and C-W Jeung. 2012. Leadership development in Korea: a Delphi study, Asia Pacific Journal of Human Resources 50: 23-42.

De Haan, E. and Y. Burger. 2005. Coaching with Colleagues: An Action Guide for One-toOne Learning. Basingstoke: Palgrave Macmillan.

De Jong, J.A., F.J. Leenders, and J.G.L. Thijssen. 1999. HRD tasks for first-level managers. Journal of Workplace Learning 11, no. 5: 176-183.

Ellinger, A. D., A.E. Ellinger and S.B. Keller. 2005. Supervisory coaching behavior, employee satisfaction, and warehouse employee performance: a dyadic perspective in the distribution industry. Human Resource Development Quarterly 14, no. 4: 435457. 
Ellinger, A.D., A.E. Ellinger, D.G. Bachrach, Y.L. Wang and A.B. Elmadagbas. 2011. Organizational investments in social capital, managerial coaching, and employee work-related performance. Management Learning 42, no. 1: 67-85.

Ellinger, A.D., R.G. Hamlin, and R.S. Beattie. 2008. Behavioural indicators of ineffective managerial coaching: A cross national study. Journal of European Industrial Training 32, no. 4: 240-257.

Felfe, J. and B. Schyns. 2006. Personality and the perceptions of transformational leadership: the impact of extraversion, neuroticism, personal need for structure and occupational self-efficacy. Journal of Applied Psychology 36, no. 3: 708-739.

Fiske, S.T. and S.E. Taylor. 2008. Social cognition: From brains to culture. New York: McGraw-Hill.

Garavan, T.N., J.P. Wilson, C. Cross, R. Carbery, I. Sieben, A. de Grip, C. Strandberg, C. Gubbins, V. Shanahan, C. Hogan, M. McCracken and N. Heaton. 2008. Mapping the context and practice of training, development and HRD in European call centres. Journal of European Industrial Training, 32 , no. 8: 612 - 728.

Gould-Williams, J.S. and M. Gatenby. 2010. The effects of organisational context and teamworking activities on performance outcomes. Public Management Review 12, no. 6: 759-787.

Graen, G. B. and M. Uhl-Bien. 1995. Relationship based approach to leadership: development of leader-member exchange (LMX) theory of leadership over 25 years: applying a multi-level, multi-domain approach. Leadership Quarterly 6, no.2: 219247.

Grant, A. M. 2007. Enhancing coaching skills and emotional intelligence through training, Industrial and Commercial Training 39, no.5: 257-266.

Grant, A.M. 2010. It takes time: a stages of change perspective on the adoption of workplace coaching skills. Journal of Change Management 10, no.1: 61-77.

Gray, D.E. 2006. Executive coaching: Towards a dynamic alliance of psychotherapy and transformative learning processes. Management Learning 37, no.4: 475-497.

Greenleaf, R.K. 2002. Servant Leadership: A Journey Into the Nature of Legitimate Power and Greatness. New Jersey: Paulist Press International.

Gregory, J.B and P.E. Levy. 2010. Employee coaching relationships: enhancing construct clarity and measurement, Coaching: An International Journal of Theory, Research and Practice 3, no.2: 109-123. 
Griffin, B., and B. Hesketh. 2003. Adaptable behaviours for successful work and career Adjustment. Australian Journal of Psychology 55: 65-73.

Griffiths, K. and M. Campbell. 2008. Regulating the regulators: paving the way for international, evidence-based coaching standards. International Journal of Evidence Based Coaching and Mentoring 6, no.1: 19-31.

Grint, K. 2005. Leadership: Limits and Possibilities. Basingstoke: Palgrave Macmillan.

Hagen, M. and M.G. Aguila. 2012. The impact of managerial coaching on learning outcomes within the team context: an analysis. Human Resource Development Quarterly 23, no. 3: 363-388.

Hamlin, R. G., A.D. Ellinger, R.S. Beattie. 2006. Coaching at the heart of managerial effectiveness: A cross-cultural study of managerial behaviors. Human Resource Development International 9, no. 3: 305-331.

Hamlin, R.G., A.D. Ellinger and R.S. Beattie. 2008. The emergent 'coaching industry: a wake-up call for HRD professionals. Human Resource Development International 11, no. 3: 287-305.

Harney, B. and C. Jordan. 2008. Unlocking the black box: line managers and HRMPerformance in a call centre context. International Journal of Productivity and Performance Management 57, no. 4: 275 - 296.

Hartog, D.N.D., A. Caley and P. Dewe. 2007. Recruiting leaders: an analysis of advertisements. Human Resource Management Journal 17, no. 1: 58-75.

Hawkins, P. and N. Smith. 2006. Coaching, Mentoring and Organizational Consultancy: Supervision and Development. Maidenhead: Open University Press.

Heslin, P.A., D. Vandewalle. and G.P. Latham. 2006. Keen to help? Managers implicit person theories and their subsequent employee coaching. Personnel Psychology 59: 871-902.

Hodgetts, W. H. 2002. Using executive coaching in organizations: What can go wrong (and how to prevent it) in C. Fitzgerald and J. Garvey Berger (eds.). Executive coaching: Practices and perspectives. Davies-Black: Palo Alto, CA.

Ives, Y. 2008. What is coaching? An exploration of conflicting paradigms. International Journal of Evidence Based Coaching and Mentoring 6, no. 2: 100-113.

Jackson, P. 2005. How do we describe coaching? An exploratory development of a typology of coaching based on the accounts of UK-based practitioners. International Journal of Evidence Based Coaching and Mentoring 3, no. 2: 45-60. 
Kang, D. and J. Stewart. 2007. Leader-member exchange (LMX) theory of leadership and HRD: Development of units of theory and laws of interaction. Leadership and Organization Development Journal 28, no.6: 531 - 551.

Kark, R. and D. Van-Dijk. 2007. Motivation to lead, motivation to follow: The role of the self-regulatory focus in leadership processes. Academy of Management Journal 32: $500-528$.

Keegan, A., M. Huemann and R.J. Turner. 2012. Beyond the line: exploring the HRM responsibilities of line managers, project managers and the HRM department in four project-oriented companies in the Netherlands, Austria, the UK and the USA. The International Journal of Human Resource Management 23, no. 15: 3085 - 3104.

Kulik, C.T. and H.T.J. Bainbridge. 2006. HR and the line: The distribution of HR activities in Australian organisations. Asia Pacific Journal of Human Resources 44, no. 2: 240256.

Ladyshewsky, R.K. 2010. The manager as coach as a driver of organizational development. Leadership and Organization Development Journal 31, no.4: 292-306.

Larsen, H.H. and C.Brewster. 2003. Line management responsibility for HRM: what is happening in Europe?. Employee Relations 25, no.3: 228-244.

Liden, R. C. and J.M. Maslyn. 1998. Multidimensionality of leader-member exchange: an empirical assessment through scale development. Journal of Management 24, no.1: 43-72.

Liao, H., D. Liu and R. Loi. 2010. Looking at both sides of the social exchange coin: a social cognitive perspective on the joint effects of relationship quality and differentiation on creativity. Academy of Management Journal 53, no. 5: 1090-1099.

Liu, X. and R. Batt. 2010. How supervisors influence performance: a multilevel study of coaching and group management in technology-mediated services. Personnel Psychology 63, no.2: 265-298.

London, M. and J.W. Smither. 2002. Feedback orientation, feedback culture, and the longitudinal performance management process. Human Resource Management Review 12: 81-100.

Mavor, P., E. Sadler-Smith and D.E. Gray. 2010. Teaching and learning intuition: some implications for HRD and coaching practice. Journal of European Industrial Training 34, nos. 8/9: 822-838. 
McCartney, W. W. and C.R. Campbell. 2006. Leadership, management, and derailment: A model of individual success and failure. Leadership and Organization Development Journal, 27. no. 3: 190 - 202.

McCauley, C.D., W.H. Drath, C.J. Palus, P.M.G. O’Connor. and B.A. Baker. 2006. The use of constructive developmental theory to advance the understanding of leadership. The Leadership Quarterly, 17: 634-653.

McGuire, D., L. Stoner and S. Mylona. 2008. The role of line managers as human resource agents in fostering organizational change in public services. Journal of Change Management 8, no. 1: 73-84.

McLean, G.N., B. Yang, M.H.C. Kuo, A.S. Tolbert, A.S. and Larkin, C. 2005. Development and Initial Validation of an Instrument Measuring Managerial Coaching Skill. Human Resource Development Quarterly 16, no. 2: 157-178.

Mehra, A., B.R. Smith, A.L. Dixon and B. Robertson. 2006. Distributed leadership in teams: The network of leadership perceptions and team performance. The Leadership Quarterly 17, no. 3: 232-245.

Meinal, J.R., S.R. Ehrlich and J. Dukerich. 1987. The romance of leadership and the evaluation of organizational performance. Academy of Management Review 12, no. 1: 91-109.

Moss, S. A., N. Dowling and J. Callanan. 2009. Towards an integrated model of leadership and self regulation. Leadership Quarterly 20: 162-176.

Nielson, K. and F. Munir. 2009. How do transformational leaders influence followers' affective well-being? Exploring the mediating role of self-efficacy. Work and Stress 23, no. 4: 313-329.

Noer, . M., C.R. Leupold and M. Valle. 2007. An Analysis of Saudi Arabian and U.S. Managerial Coaching Behaviors. Journal of Managerial Issues, 19, no. 2: 271-287.

O'Donnell, M., G. Yukl and T. Taber. 2012. Leader behavior and LMX: a constructive replication. Journal of Managerial Psychology 27, no.2: 143 - 154.

Peterson, D.B. and B. Little. 2005. Invited reaction: development and initial validation of an instrument measuring managerial coaching skill. Human Resource Development Quarterly, 16, no. 2: 179-184.

Piccolo, R.F. and J. A. Colquitt. 2006. Transformational leadership and job behaviour: the mediating role of core job characteristics. Academy of Management Journal 49, no. 2: $327-340$ 
Purcell, J. and S. Hutchinson. 2007. Front-line managers as agents in the HRM-performance causal chain: theory, analysis and evidence. Human Resource Management Journal 17, no. 1: 3-20.

Rigotti, T. and B. Schyns. 2008. A short version of the occupational self-efficacy scale: Structural and construct validity across five countries. Journal of Career Assessment 16, no. 2: 238-255.

Russell, R.F. and A.G. Stone. 2002. A review of servant leadership attributes: developing a practical model. Leadership and Organisation Development Journal 23: 145-157.

Segers, J., D. Vloeberghs and E. Henderickx. 2011. Structuring and understanding the coaching industry: the coaching cube. Academy of Management Learning and Education 10, no. 2: 204-221.

Shondrick, S.J., J.E. Dinh and R.G. Lord. 2010. Developments in implicit leadership theory and cognitive science: Applications to improving measurement and understanding alternatives to hierarchical leadership. The Leadership Quarterly 21, no. 6: 959-978.

Sivanathan, N., K.A. Arnold, N. Turner and J. Barling. 2004. Leading well: transformational leadership and well-being, in P.A. Linley and S. Joseph (eds). Positive Psychology in Practice. New York: Wiley: 241-255.

Sparrowe, R.T. and R.C. Liden. 1997. Process and structure in leader-member exchange. Academy of Management Review 22: 522-52.

Stewart, M.M. and O.E. Johnson. 2009. Leader-Member Exchange as a Moderator of the Relationship Between Work Group Diversity and Team Performance. Group and Organization Management 34: 507-535.

Sue-Chan, C., Z. Chen and W. Lam. 2011. LMX, Coaching Attributions, and Employee Performance. Group and Organization Management 36, no.4: 466-498.

Stoker, J. I. 2008. Effects of team tenure and leadership in self-managing teams. Personnel Review 37, no. 5: 564-582.

Valcea, S., M.R. Hamdani, M.R Buckley and M.M. Novicevic. 2011. Exploring the developmental potential of leader-follower interactions: a constructive-developmental approach. The Leadership Quarterly 22:604-615.

Wakefield, M. 2006. New views on leadership coaching. The Journal for Quality and Participation 29, no. 2: 9-12.

Watson, S. and G. Maxwell. 2007. HRD from a functionalist perspective: The views of line managers. Advances in Developing Human Resources 9: 31-41. 
Yukl, G. 1999. An evaluation of conceptual weaknesses in transformational and charismatic leadership theories. Leadership Quarterly 10:285-305.

Yukl, G. 2008. How leaders influence organizational effectiveness. The Leadership Quarterly 19: $708-722$

Yukl, G., M. O'Donnell and T. Taber. 2009. Influence of leader behaviors on the leadermember exchange relationship. Journal of Managerial Psychology 24, no.4: 289-99.

Zagenczyk, T.J., R. Gibney, C. Kiewitz and S.L.D. Restuborg. 2009. Mentors, supervisors and role models: do they reduce the effects of psychological contract breach? Human Resource Management Journal 19, no. 3: 237-259.

Table 1: Participating organisations

\begin{tabular}{|c|l|c|c|}
\hline $\begin{array}{c}\text { Organisation } \\
\text { identifier }\end{array}$ & \multicolumn{1}{|c|}{ Sector } & \multicolumn{1}{|c|}{ Size } & $\begin{array}{c}\text { \% of respondents } \\
\text { within respondent } \\
\text { group }\end{array}$ \\
\hline A & Not-for profit (Social care) & Small & 3 \\
\hline B & Not-for-profit (Social care) & Large & 5 \\
\hline C & $\begin{array}{l}\text { Not-for-profit (Professional } \\
\text { organisation) }\end{array}$ & Small & 8 \\
\hline D & $\begin{array}{l}\text { Public (Government } \\
\text { Department) }\end{array}$ & Large & 27 \\
\hline E & Public (Education) & Large & 7 \\
\hline F & Private (Transport - rail) & Large & 26 \\
\hline G & Private (Engineering) & Large & 8 \\
\hline H & Private (Transport - Sea) & Small & 3 \\
\hline I & Private (Pharmaceuticals) & Large & 4 \\
\hline K & Private (Transport - Air) & Small & 8 \\
\hline
\end{tabular}

${ }^{*}$ Large $=1,000+$ employees; medium $=250-1,000$ employees $;$ small $=$ fewer than 250 employees 
Table 2: Principal component analysis

Rotated Component Matrix ${ }^{\mathrm{a}}$

\begin{tabular}{|l|r|r|r|r|}
\hline \multicolumn{1}{|c|}{ Coaching behaviours (4 point scale) } & \multicolumn{1}{c|}{ Mean } \\
\hline \multicolumn{1}{|c|}{$\mathrm{n}=521$}
\end{tabular}

Extraction Method: Principal Component Analysis.

Rotation Method: Varimax with Kaiser Normalization.

a. Rotation converged in 4 iterations. 
Table 3: Correlation analysis

\begin{tabular}{|c|c|c|c|c|c|c|c|c|c|c|}
\hline & & Gender & Age & $\begin{array}{c}\text { Direct } \\
\text { reports }\end{array}$ & Seniority & Quals & Tenure & $\begin{array}{c}\text { Core } \\
\text { Coach- } \\
\text { ing }\end{array}$ & LMX & OSE \\
\hline \multirow[t]{2}{*}{ Gender } & $\begin{array}{l}\text { Pearson } \\
\text { Correlation }\end{array}$ & 1.000 & $-.179^{* *}$ & $-.236^{\star *}$ & -.066 & -.053 & -.056 & $.122^{* *}$ & .040 & -.031 \\
\hline & Sig. (2-tailed) & & .000 & .000 & .130 & .223 & .204 & .005 & .362 & .484 \\
\hline \multirow[t]{2}{*}{ Age } & PearsonCorrelation & & 1.000 & -.034 & $.156^{\star \pi}$ & .065 & $.275^{\star x}$ & -.033 & .036 & -.012 \\
\hline & Sig. (2-tailed) & & & .445 & .000 & .136 & .000 & .459 & .419 & .791 \\
\hline \multirow[t]{2}{*}{$\begin{array}{l}\text { Direct } \\
\text { reports }\end{array}$} & $\begin{array}{l}\text { Pearson } \\
\text { Correlation }\end{array}$ & & & 1.000 & $-.136^{\star *}$ & .003 & .068 & $-.120^{* *}$ & .009 & .075 \\
\hline & Sig. (2-tailed) & & & & .002 & .942 & .122 & .006 & .841 & .087 \\
\hline \multirow[t]{2}{*}{ Seniority } & $\begin{array}{l}\text { Pearson } \\
\text { Correlation }\end{array}$ & & & & 1.000 & $.297^{* *}$ & -.073 & .070 & .040 & .051 \\
\hline & Sig. (2-tailed) & & & & & .000 & .098 & .109 & .363 & .248 \\
\hline \multirow[t]{2}{*}{ Quals } & $\begin{array}{l}\text { Pearson } \\
\text { Correlation }\end{array}$ & & & & & 1.000 & .050 & .083 & .045 & $.101^{\star}$ \\
\hline & Sig. (2-tailed) & & & & & & .252 & .057 & .300 & .021 \\
\hline \multirow[t]{2}{*}{ Tenure } & $\begin{array}{l}\text { Pearson } \\
\text { Correlation }\end{array}$ & & & & & & 1.000 & $.110^{*}$ & .052 & $.095^{*}$ \\
\hline & Sig. (2-tailed) & & & & & & & .012 & .237 & .030 \\
\hline \multirow[t]{2}{*}{$\begin{array}{l}\text { Core } \\
\text { Coaching }\end{array}$} & $\begin{array}{l}\text { Pearson } \\
\text { Correlation }\end{array}$ & & & & & & & 1.000 & $389^{* \star}$ & $.422^{* *}$ \\
\hline & Sig. (2-tailed) & & & & & & & & .000 & .000 \\
\hline \multirow[t]{2}{*}{ LMX } & $\begin{array}{l}\text { Pearson } \\
\text { Correlation }\end{array}$ & & & & & & & & 1.000 & $-.376^{* *}$ \\
\hline & Sig. (2-tailed) & & & & & & & & & .000 \\
\hline \multirow[t]{2}{*}{ OSE } & $\begin{array}{l}\text { Pearson } \\
\text { Correlation }\end{array}$ & & & & & & & & & 1.000 \\
\hline & Sig. (2-tailed) & & & & & & & & & \\
\hline
\end{tabular}

**. Correlation is significant at the 0.01 level (2-tailed).

*. Correlation is significant at the 0.05 level (2-tailed).

Table 4: Stepwise regression analysis

\begin{tabular}{|c|c|c|c|c|c|c|}
\hline \multirow[t]{2}{*}{ Model } & \multirow{2}{*}{$\begin{array}{c}\text { Standardized } \\
\text { Coefficients } \\
\text { Beta } \\
\end{array}$} & \multirow[b]{2}{*}{ Sig. } & \multicolumn{2}{|c|}{$95.0 \%$ Confidence Interval for B } & \multicolumn{2}{|c|}{ Collinearity Statistics } \\
\hline & & & Lower Bound & Upper Bound & Tolerance & VIF \\
\hline (Constant) & & .000 & 2.275 & 2.752 & & \\
\hline OSE & -.330 & .000 & -.304 & -.186 & .847 & 1.180 \\
\hline LMX & -.258 & .000 & -.185 & -.098 & .855 & 1.169 \\
\hline Direct reports & -.130 & .001 & -.001 & .000 & .937 & 1.067 \\
\hline Gender & .096 & .014 & .019 & .168 & .940 & 1.064 \\
\hline Tenure in this position & .080 & .035 & .004 & .100 & .985 & 1.015 \\
\hline
\end{tabular}

a. Dependent Variable: Core Coaching

$F_{5,515}=39.151 . P<0.0005$, Adjusted R Square $=0.268$

Adjusted R Square $=0.268$

OSE $F=121.3$

$\mathrm{LMX} F=83.0$. 
